\title{
MÉTODO MICROBIOLÓGICO PARA DETERMINAÇÃO DA POTÊNCIA DE ANTIMICROBIANOS
}

\section{A MICROBIOLOGICAL ASSAY FOR DETERMINING THE POTENCY OF ANTIMICROBIALS}

\author{
Luís Antônio Esmerino ${ }^{1}$, Airton Vicente Pereira ${ }^{2}$, Taísa Adamowicz ${ }^{3}$, \\ Danielly Machado Borges ${ }^{3}$, Elisane Antunes Talacimon ${ }^{3}$, Meri Elen Schelesky ${ }^{3}$
}

1 Autor para contato: Universidade Estadual de Ponta Grossa - UEPG, Campus em Uvaranas, Departamento de Análises Clínicas e Toxicológicas, Ponta Grossa, PR, Brasil; (42) 220-3113; e-mail: esmerino@uepg.br

2 Universidade Estadual de Ponta Grossa, Campus em Uvaranas, Departamento de Ciências Farmacêuticas, Ponta Grossa, PR, Brasil; e-mail: airtonvp@uepg.br

3 Universidade Estadual de Ponta Grossa, Campus em Uvaranas, Departamento de Ciências Farmacêuticas - PIBIC/CNPq/UEPG

Recebido para publicação em 23/10/2003

Aceito para publicação em 24/03/2004

\section{RESUMO}

No presente trabalho, tomando por base os compêndios oficiais farmacêuticos, utilizou-se o método microbiológico de cilindro em placas para determinação da potência de três antimicrobianos: cefalexina, ciprofloxacina e eritromicina. Para o ensaio com a cefalexina utilizou-se o microrganismo-teste Staphylococcus aureus ATCC 25923, soluções de 10, 20 e $40 \mu \mathrm{g} / \mathrm{mL}$ e a curva obtida apresentou coeficiente de correlação próximo da unidade com $\mathrm{r}^{2}=0,9754$. Para a ciprofloxacina Staphylococcus aureus ATCC 25923 e Escherichia coli ATCC 25922 foram utilizados. Os padrões foram de 2,5 , 5,0 , 10 e $20 \mu \mathrm{g} / \mathrm{mL}\left(\mathrm{r}^{2}=0,9885\right)$ e 1,0 , 2,5 , 5,0 e $10 \mu \mathrm{g} / \mathrm{mL}$ $\left(\mathrm{r}^{2}=0,9946\right)$, respectivamente. No teste para eritromicina utilizou-se Micrococcus luteus ATCC 9341 e soluções de 0,5; 0,75; 1,0; 1,25 e 1,5 ㅆg/ $\mathrm{mL}\left(\mathrm{r}^{2}=0,9907\right)$. Para todos os antimicrobianos os coeficientes de variação obtidos com os diâmetros dos halos de inibição ficaram abaixo de $5 \%$ indicando adequada precisão. Este estudo tem a finalidade de servir como referência para o doseamento desses fármacos, e observando o desenvolvimento do método e os resultados obtidos, foi possível concluir que o ensaio microbiológico de cilindros em placa, nas condições analisadas, é adequado, econômico e de fácil aplicação, podendo ser utilizado para a determinação da potência de antimicrobianos em preparações farmacêuticas. 
Palavras-chave: antimicrobianos; método microbiológico; cilindros em placas; potência; validação

\begin{abstract}
In this study we describe a research in which the cylinder-plate method is applied in order to determine the potency of three antibiotics: cephalexin, ciprofloxacin, and erythromycin. In the first assay, a strain of strain of Staphylococcus aureus ATCC 25923 was used as the testing organism, with the antibiotic cephalexin at concentrations ranging from 10 to 20 and $40 \mu \mathrm{g} /$ $\mathrm{mL}$. A prospective validation of the method showed that it was linear $\left(\mathrm{r}^{2}=\right.$ 0,9754). For the dosing of ciprofloxacin two microorganisms were used: S. aureus ATCC 25923 and E. coli ATCC 25922 . The solutions were 2.5, 5.0, 10 and $20 \mu \mathrm{g} / \mathrm{mL}\left(\mathrm{r}^{2}=0.9885\right)$ and 1.0, 2.5, 5.0 and $10 \mu \mathrm{g} / \mathrm{mL}\left(\mathrm{r}^{2}=0.9946\right)$. In the third assay, the microorganism Micrococcus luteus ATCC 9341 was used, and in order to obtain the reference curve, erythromycin solutions of 0.5 , $0.75,1.0,1.25$ and $1.5 \mu \mathrm{g} / \mathrm{mL}\left(\mathrm{r}^{2}=0.9907\right)$ were used. The results obtained led us to conclude that the microbiological cylinder-plate method is valid to determine the dosing of antimicrobials.
\end{abstract}

Key words: antimicrobial, cylinder-plate method, microbiology assay, diffusion method assay, potency determination

\section{Introdução}

No estudo dos antimicrobianos e no tratamento das doenças infecciosas, os conceitos de sensibilidade e resistência bacteriana se fundamentam na correlação entre a concentração inibitória mínima (CIM) e os níveis plasmáticos alcançados com o antimicrobiano administrado. De certa forma, a CIM é correlacionada com as concentrações sanguíneas e/ou teciduais obtidas com esquemas posológicos seguros, afirmando-se que há sensibilidade quando a CIM é inferior a essas concentrações (Fuchs e Wannmacher, 1998).

Para se obter concentrações terapêuticas com a capacidade de matar ou inibir o crescimento bacteriano é necessário que a potência do antimicrobiano esteja adequada nas preparações farmacêuticas que serão administradas ao paciente, cuja infecção se deseja combater. Nesse aspecto, é crescente a preocupação com a qualidade dos medicamentos, em especial a questão dos genéricos, a bioequivalência e a estabilidade das formulações (Luiza et al., 1999).

A potência dos antibióticos geralmente é determinada, comparando-se a dose com a qual se inibe o crescimento de um microrganismo adequado e susceptível com a dose da preparação do antibiótico de referência nas mesmas condições de trabalho. Uma redução na atividade microbiana pode revelar mudanças não demonstráveis por métodos químicos (UNITED STATES PHARMACOPEIAL, 1990).

Os métodos microbiológicos geralmente utilizam um padrão de referência para se determinar uma possível perda da atividade antimicrobiana. A Farmacopéia Americana recomenda a utilização de procedimentos microbiológicos para a determinação da potência dos antibióticos nas apresentações farmacêuticas.

Geralmente são empregados dois métodos, o do cilindro em placa ou de "placa" e o turbidimétrico ou de "tubo". O primeiro se baseia na 
difusão do antibiótico contido em um cilindro vertical, através de uma camada de ágar solidificado em uma placa de Petri, em uma extensão tal, que o crescimento do microrganismo agregado se detenha em uma área circular ou "zona” ao redor do cilindro que contém a solução do antibiótico. O método turbidimétrico se baseia na inibição do crescimento de um cultivo microbiano em uma solução uniforme do antibiótico, em um caldo que favorece o seu rápido crescimento na ausência desse fármaco.

A determinação da potência dos antimicrobianos é importante no controle e na garantia da qualidade das preparações farmacêuticas e faz-se necessário o desenvolvimento de procedimentos práticos e econômicos que possam ser validados e aplicados no doseamento desses fármacos.

No presente estudo, baseando-se na literatura existente (FARMACOPÉIA Brasileira, 1988; UNITED STATES PHARMACOPEIAL, 1990; Fröehlich e Schapoval, 1990; Breier et al., 2002), testou-se o método microbiológico de cilindro em placas para a determinação da potência dos antimicrobianos: cefalexina, ciprofloxacina e eritromicina.

Após o estabelecimento do procedimento padrão, o mesmo poderá ser validado e aplicado na determinação da potência desses antimicrobianos nas diferentes apresentações farmacêuticas como comprimidos, cápsulas, soluções e suspensões.

\section{Material e métodos}

O método empregado foi o de difusão em ágar-cilindro em placas (UNITED STATES PHARMACOPEIAL, 1990; Fröehlich e Schapoval, 1990; Turcinov e Pepeljnjak, 1998; Breier et al., 2002) e diferentes concentrações (padrões) dos antimicrobianos estudados foram utilizadas com o objetivo de traçar uma curva que demonstre a relação entre o diâmetro dos halos de inibição e a potência do antimicrobiano.

\section{Cefalexina}

Para a cefalexina, utilizou-se o meio de cultura ágar Mueller-Hinton e o microrganismo-teste Staphylococcus aureus ATCC 25923.
A solução padrão foi preparada com $50 \mathrm{mg}$ de cefalexina em um balão volumétrico de $50 \mathrm{~mL}$. Dilui-se com tampão fosfato pH 6,0, obtendo-se uma solução com concentração de $1000 \mu \mathrm{g} / \mathrm{mL}$. À partir dessa solução foram realizadas diluições até se obter as concentrações de 10, 20 e $40 \mu \mathrm{g} / \mathrm{mL}$. A validade dessas soluções foi de sete dias, em geladeira.

No preparo do inóculo, inicialmente, foi feita uma suspensão bacteriana, utilizando uma cultura recente (máximo 24 horas) em tampão fosfato $\mathrm{pH}$ 6,0. A concentração do inóculo foi padronizada, comparando a turbidez do inóculo com o padrão 0,5 da escala de MacFarland em espectrofotômetro (580 nm). Essa turvação é semelhante à padronizada para o antibiograma e o resultado da absorbância deve estar entre 0,08 e 0,10 , o que equivale a $1,5 \mathrm{x}$ $10^{8} \mathrm{UFC} / \mathrm{mL}$ (UNITED STATES PHARMACOPEIAL, 1990 ; NCCLS, 2002).

A partir dessa suspensão, foi preparado o ágar-inóculo numa proporção de $1,0 \mathrm{~mL}$ da suspensão bacteriana para $100 \mathrm{~mL}$ do meio ágar Mueller-Hinton ainda no estado líquido, porém numa temperatura suportável à palma da mão humana (45$50^{\circ} \mathrm{C}$ ), em que os microrganismos permanecem vivos ao serem adicionados e homogeneizados com o meio.

Antes de se verter o meio de cultura sobre as placas, foram colocados papéis de filtro esterilizados nas tampas das mesmas para que a água resultante do metabolismo bacteriano fosse absorvida. Isso deve sempre ser feito para evitar que a água que evapora fique retida na tampa da placa e caia sobre o meio, diluindo os antibióticos adicionados nos cilindros, o que poderia alterar os diâmetros dos halos de inibição.

Para preparar as placas, foram vertidos 15 $\mathrm{mL}$ do ágar Muller-Hinton em placas de $100 \mathrm{~mm}$. Homogeneizou-se e esperou-se solidificar. Sobre essa camada de meio, foram adicionados $5 \mathrm{~mL}$ do ágar-inóculo.

Com as duas camadas de meio uniformemente sobrepostas e já solidificadas, foram colocados, sobre a superfície do meio, os cilindros de aço inoxidável (10 mm de altura; diâmetros interno e externo de 6 e $8 \mathrm{~mm}$, respectivamente), a uma distância de aproximadamente $30 \mathrm{~mm}$ um do outro. Os cilindros foram previamente lavados, 
colocados em uma solução de ácido nítrico $2 \mathrm{~N}$ e esterilizados em autoclave $120^{\circ} \mathrm{C}$ por 15 minutos.

As curvas foram realizadas em quatro etapas, com a utilização de 20 placas sendo 5 por curva. Em cada placa foram colocados três cilindros com as soluções diluídas do padrão nas concentrações de 10, 20 e $40 \mu \mathrm{g} / \mathrm{mL}$, rotuladas como P1, P2 e P3, respectivamente. O volume pipetado no interior dos cilindros foi de $150 \mu \mathrm{L}$.

É conveniente aguardar alguns minutos após a colocação das soluções no interior dos cilindros sobre o meio para que ocorra a sua difusão. Então, cuidadosamente, colocou-se as placas na estufa $35^{\circ} \mathrm{C}$, com as tampas para cima e de preferência sem empilhá-las. Caso a estufa seja bastante utilizada e isso implique em sua abertura várias vezes ao dia, o fundo da estufa deve ser o local mais recomendado para a incubação das placas, onde não há tanta perda de calor e alteração de temperatura.

\section{Ciprofloxacina}

Para determinação da potência da ciprofloxacina dois microrganismos-teste foram utilizados: Staphylococcus aureus ATCC 25923 (A) e Escherichia coli ATCC 25922 (B). As suspensões dos microrganismos (A e B) foram preparadas em tampão fosfato $\mathrm{pH}$ 8,0 e o procedimento para o preparo do inóculo e das placas foi semelhante ao utilizado para a cefalexina.

A solução padrão foi preparada com $50 \mathrm{mg}$ de ciprofloxacina em um balão volumétrico de 50 mL. Em seguida, dissolveu-se em $10 \mathrm{~mL}$ de $\mathrm{NaOH}$ 0,1 M sob agitação, e o volume foi completado com tampão fosfato $\mathrm{pH}$ 8,0 para se obter uma solução com a concentração de 1000 g/mL. Na seqüência, diluições foram realizadas até a obtenção das concentrações de 2,5 , 5,0 , 10 e $20 \mu \mathrm{g} / \mathrm{mL}$ e 1,0 , 2,5 , 5,0 e $10 \mu \mathrm{g} / \mathrm{mL}$ para A e B, respectivamente.

Foram utilizadas 21 placas, sendo 18 placas para A, com 9 repetições para cada concentração, dois cilindros por placa (duas placas por curva), e 3 placas para $\mathrm{B}$, com quatro cilindros (uma placa por curva), preenchidos com $100 \mu \mathrm{L}$ das soluções.

\section{Eritromicina}

Na determinação da potência microbiológica da eritromicina empregou-se o meio de cultura número 11 de Grove-Randall e o microrganismo Micrococcus luteus ATCC 9341.

A solução padrão foi preparada com $50 \mathrm{mg}$ de eritromicina, em um balão volumétrico de $50 \mathrm{~mL}$. Para a solubilização, foram adicionados $2 \mathrm{~mL}$ de metanol; e completou-se com tampão fosfato de potássio 0,1 M, pH 8,0, para se obter uma solução com a concentração de $1000 \mu \mathrm{g} / \mathrm{mL}$. A partir dessa solução padrão, foram feitas diluições (com o mesmo tampão) até se obter soluções com as concentrações finais de 0,$5 ; 0,75 ; 1,0 ; 1,25$ e 1,5 $\mu \mathrm{g} / \mathrm{mL}$, rotuladas como P1, P2, P3, P4 e P5, respectivamente. Essas soluções se mantiveram estáveis por dois dias em geladeira.

A concentração do inóculo foi preparada em tampão fosfato $\mathrm{pH}$ 8,0 e a padronização da suspensão bacteriana foi realizada em espectrofotômetro com comprimento de onda de $580 \mathrm{~nm}$ e transmitância de $25 \%$. O ágar-inóculo foi preparado com 1,5 mL dessa suspensão e $100 \mathrm{~mL}$ do meio (UNITED STATED PHARMACOPEIAL, 1990).

Para o ensaio, 24 placas foram utilizadas, com dois e três cilindros por placa, preenchidos com 175 $\mu \mathrm{L}$.

Todas as placas foram incubadas por 18-20 horas a $35^{\circ} \mathrm{C}$ e os diâmetros dos halos de inibição foram determinados em milímetros (mm).

\section{Resultados}

Os resultados obtidos com as soluções padrão de cefalexina, eritromicina e ciprofloxacina são apresentados na seqüência.

\section{Cefalexina}

Foram plotados no gráfico "logarítimo da concentração versus diâmetro dos halos” os pontos relativos às medias dos halos obtidos. Os resultados referentes aos diâmetros dos halos, o desvio padrão e os coeficientes de variação (\%) podem ser observados na tabela 1 . O gráfico que mostra a curva obtida está representado na figura 1. 
Tabela 1 - Resultado da leitura dos halos de inibição obtidos com os diferentes padrões de cefalexina.

\begin{tabular}{l|ccc}
\hline \multicolumn{1}{c|}{ MICRORGANISMO } & \multicolumn{3}{c}{ CEFALEXINA $(\mu \mathbf{g} / \mathbf{m L})$} \\
\hline Staphylococcus aureus ATCC $\mathbf{2 5 9 2 3}$ & $\mathbf{1 0}$ & $\mathbf{2 0}$ & $\mathbf{4 0}$ \\
Diâmetro dos halos (mm) $\mathrm{n}=4$ & $12,25( \pm 0,1)$ & $16,42( \pm 0,33)$ & $18,8( \pm 0,43)$ \\
Coeficiente de variação $(\%)$ & 0,82 & 2,01 & 2,29 \\
\hline
\end{tabular}

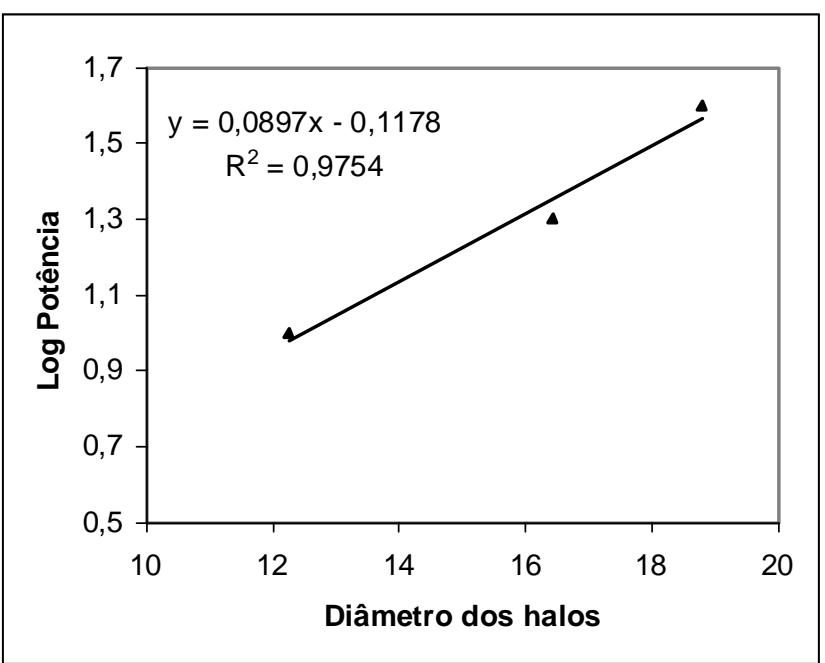

Figura 1 - Curva de calibração com cefalexina e o microrganismo-teste Stphylococcus aureus ATCC 25923.

\section{Eritromicina}

Foram feitas 12 curvas de 5 pontos. Para traçar a curva, a concentração do padrão foi multiplicada por 10. A tabela 2 e a figura 2 mostram os resultados obtidos.

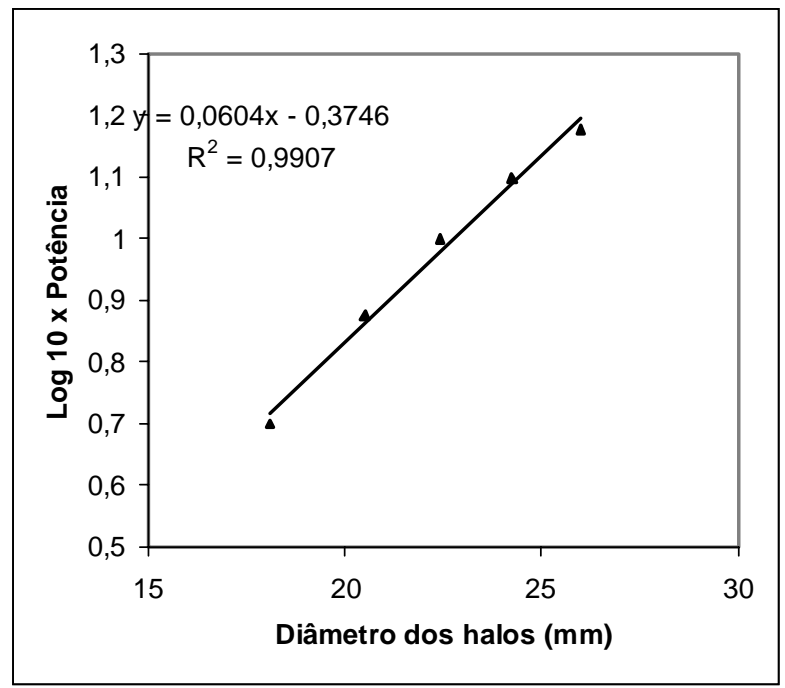

Figura 2 - Curva de calibração com eritromicina e o microrganismo-teste Micrococcus luteus ATCC 9341.

\section{Ciprofloxacina}

As curvas foram traçadas com quatro concentrações (pontos) para cada microrganismo. A figura 4 mostra uma placa com a curva obtida com Staphylococcus aureus. Os resultados obtidos para cada microrganismo podem ser observados na tabela 3 e nas figuras 3 e 5 .

Tabela 2 - Resultado da leitura dos halos de inibição obtidos com os diferentes padrões de eritromicina.

\begin{tabular}{|c|c|c|c|c|c|}
\hline MICRORGANISMO & \multicolumn{5}{|c|}{ ERITROMICINA $(\mu \mathrm{g} / \mathrm{mL})$} \\
\hline Micrococcus luteus ATCC 9341 & 0,5 & 0,75 & 1,0 & 1,25 & 1,5 \\
\hline Diâmetro dos halos (mm) n=12 & $18,08( \pm 0,7)$ & $20,50( \pm 0,9)$ & $22,42( \pm 0,8)$ & $24,25( \pm 0,6)$ & $26( \pm 0,6)$ \\
\hline Coeficiente de variação (\%) & 3,7 & 4,4 & 3,5 & 2,6 & 2,3 \\
\hline
\end{tabular}


Tabela 3 - Resultado da leitura dos halos de inibição obtidos com os diferentes padrões de ciprofloxacina.

\begin{tabular}{|c|c|c|c|c|}
\hline MICRORGANISMO & \multicolumn{4}{|c|}{ CIPROFLOXACINA $(\mu \mathrm{g} / \mathrm{mL})$} \\
\hline Staphylococcus aureus ATCC 25923 & 2,5 & 5 & 10 & 20 \\
\hline Diâmetro dos halos (mm) n=9 & $13,22( \pm 0,44)$ & $17( \pm 0,71)$ & $19,11( \pm 0,78)$ & $22,11( \pm 1,05)$ \\
\hline Coeficiente de variação (\%) & 3,33 & 4,15 & 4,09 & 4,9 \\
\hline Escherichia coli ATCC 25922 & 1 & 2,5 & 5 & 10 \\
\hline Diâmetro dos halos (mm) n=3 & $24,33( \pm 0,58)$ & $28,33( \pm 0,58)$ & $31( \pm 0)$ & $33,17( \pm 1,04)$ \\
\hline Coeficiente de variação (\%) & 2,37 & 2,0 & 0 & 3,13 \\
\hline
\end{tabular}

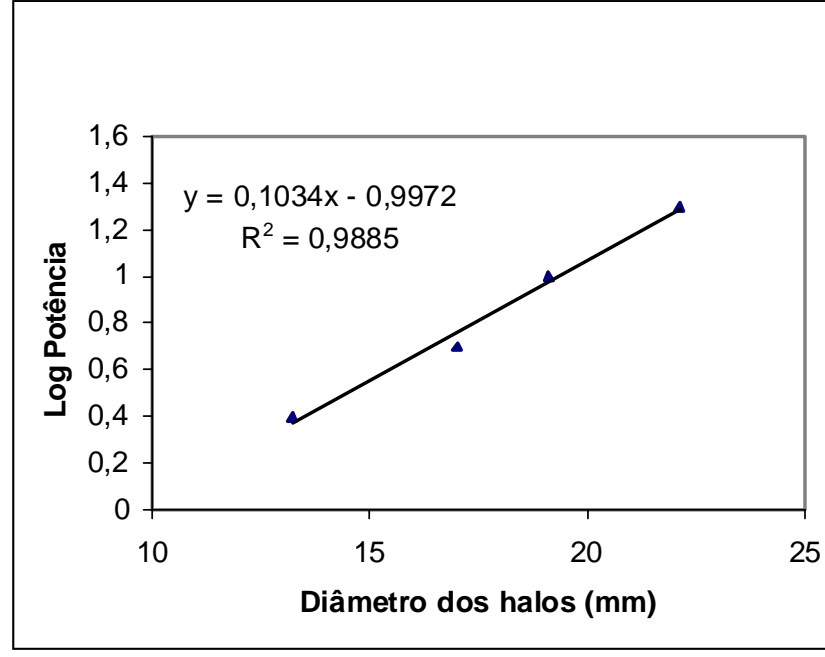

Figura 3 - Curva de calibração com ciprofloxacina e microrganismo-teste Staphylococcus aureus ATCC 25923.

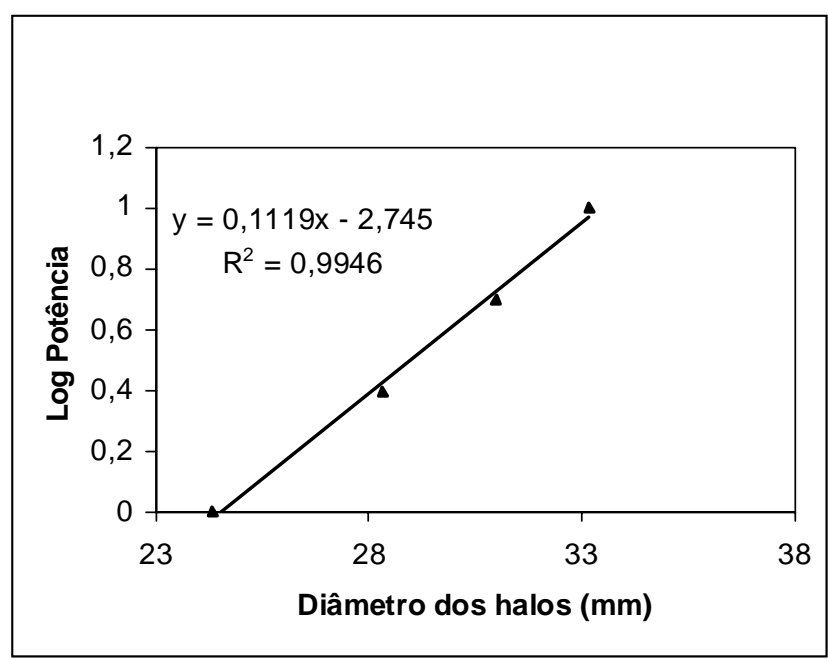

Figura 5 -Curva de calibração com ciprofloxacina e o microrganismo-teste Escherichia coli ATCC 25922.

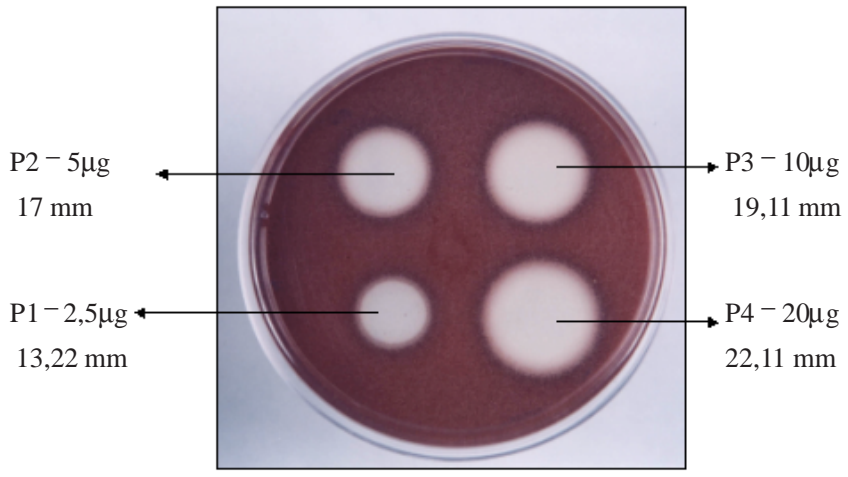

Figura 4 - Placa com os padrões de ciprofloxacina e o microrganismo-teste Staphylococcus aureus ATCC 25923.

\section{Discussão}

No presente trabalho utilizou-se o método microbiológico para a determinação da potência de antimicrobianos. Esse ensaio, embora pouco conhecido, é semelhante aos testes de difusão em ágar com discos de papel de filtro (Koneman et al, 2001). O método avalia a capacidade de um dado microrganismo de se multiplicar na presença de concentrações presumíveis de um antimicrobiano aplicado no interior de um cilindro sobre uma camada do ágar em uma placa de petri. $\mathrm{O}$ antimicrobiano se difunde no ágar, em concentrações decrescentes, e a cepa bacteriana semeada cresce até encontrar a concen- 
tração inibitória mínima, e a partir do ponto de aplicação se forma um halo de inibição ao redor do cilindro. Esse halo é determinado em milímetros e é diretamente proporcional à concentração do antimicrobiano. Assim, à medida que se aumenta a concentração do antimicrobiano, são obtidos halos maiores, até que se esgote a capacidade de difusão do antimicrobiano no ágar. Nesse ponto, o aumento na concentração do antimicrobiano não mais aumenta o halo de inibição.

A cefalexina atua inibindo a síntese da parede celular de algumas bactérias e possui espectro antibacteriano semelhante à das demais cefalosporinas de primeira geração (cefalotina, cefazolina), embora seja um pouco menos ativa contra estafilococos produtores de penicilinase. Disponível para terapia oral, sua administração por essa via resulta em picos de concentração plasmática de $16 \mu \mathrm{g} / \mathrm{mL}$ após uma dose de $500 \mathrm{mg}$, que é a adequada para a inibição de muitos patógenos gram-positivos e gramnegativos sensíveis à cefalotina (Fuchs e Wannmacher, 1998; Rang et al., 2001).

Para o doseamento da cefalexina, o coeficiente de correlação apresentou-se próximo da unidade $\left(\mathrm{r}^{2}=0,9754\right)$, o que demonstra a linearidade do método. Os coeficientes de variação obtidos foram de 0,82 ; 2,01 e 2,29\%, respectivamente, conforme as diluições do padrão. Os coeficientes de variação abaixo de $5 \%$ indicam adequada precisão do método.

As fluoroquinolonas agem nas bactérias inibindo a DNA-girase, enzima que participa de um grande número de reações envolvidas no processo de replicação do DNA (Fuchs e Wannmacher, 1998). A ciprofloxacina foi escolhida devido ao seu amplo espectro de atividade antimicrobiana, abrangendo bactérias Gram-positivas e negativas. Essas características fizeram com que esses fármacos (ciprofloxacina, ofloxacina, norfloxacina) se tornassem agentes atrativos para o tratamento de enfermidades infecciosas severas, tanto no homem como em animais.

As fluoroquinolonas são bem absorvidas após administração oral e são distribuídas amplamente pelos diversos tecidos do corpo humano. Os níveis séricos máximos são alcançados dentro de l-3 horas após administração oral de uma dose de 400 mg, sendo que os níveis máximos variam de $1,5 \mu \mathrm{g} / \mathrm{mL}$ para a norfloxacina, a 5,8 $\mu \mathrm{g} / \mathrm{mL}$ para a pefloxacina (Goodman e Gilman, 1996).

Para o doseamento microbiológico da ciprofloxacina utilizou-se o método adaptado da Farmacopéia Americana. No ensaio utilizou-se Staphylococcus aureus 25923 e Escherichia coli ATCC 25922. As curvas apresentaram coeficientes de correlação próximos da unidade, sendo $\mathrm{r}^{2}=$ 0,9885 e $r^{2}=0,9946$, respectivamente. Os coeficientes de variação obtidos ficaram abaixo de $5 \%$.

A eritromicina é um antimicrobiano pertencente à categoria dos macrolídeos e foi descoberta entre os produtos metabólicos de um microorganismo denominado Streptomyces erythreus. Esse antimicrobiano foi escolhido por ser de largo espectro e de uso clínico geral. Os macrolídeos inibem a síntese de proteínas bacterianas e sua ação pode ser bactericida ou bacteriostática, dependendo da concentração e do microrganismo. Esse antibiótico pode ser utilizado no tratamento de pneumonias, conjuntivites, infecções pélvicas, gastroenterites, coqueluche, sífilis e gonorréia. O seu espectro antimicrobiano é muito semelhante ao da penicilina, e dessa forma é uma alternativa segura e eficaz para pacientes alérgicos (Rang et al., 2001).

A eritromicina base é absorvida de forma incompleta, porém adequada, pela porção superior do intestino delgado; é inativada pelo suco gástrico e por esse motivo é geralmente administrada sob a forma de cápsulas ou de comprimidos revestidos que se dissolvem no duodeno. As concentrações plasmáticas máximas são de 0,3 a 0,5 $\mu \mathrm{g} / \mathrm{mL}$, 4 horas após a administração oral de $250 \mathrm{mg}$ da base e são de 0,3 a l ,9 $\mu \mathrm{g} / \mathrm{mL}$ após uma única dose de 500 mg. Os ésteres da eritromicina base (estearato, estolato) foram sintetizados na tentativa de melhorar a estabilidade ácida e facilitar a absorção. As concentrações com o composto estearato no plasma são semelhantes às da eritromicina. $O$ estolato de eritromicina é menos sensível ao ácido do que a base e é mais bem absorvido do que as outras formas da substância. Uma única dose oral de $250 \mathrm{mg}$ de estolato de eritromicina promove concentrações plasmáticas máximas de cerca de $1,5 \mu \mathrm{g} / \mathrm{mL}$, após 
2 horas, e uma dose de $500 \mathrm{mg}$ produz concentrações máximas de $4 \mu \mathrm{g} / \mathrm{mL}$. No entanto, a concentração real de eritromicina base microbiologicamente ativa no plasma pode ser semelhante nas diversas apresentações (Goodman e Gilman, 1996).

Para a eritromicina, uma curva de cinco pontos foi traçada. O coeficiente de correlação apresentouse próximo da unidade $\left(\mathrm{r}^{2}=0,9907\right)$. Os CVs obtidos com os diâmetros dos halos de inibição ficaram abaixo de $5 \%$ e foram de 3,$7 ; 4,4 ; 3,5 ; 2,6$ e 2,3\%, respectivamente conforme as diluições do padrão. Esses valores indicam adequada precisão do ensaio.

\section{Conclusão}

A partir dos resultados obtidos, foi possível concluir que o ensaio microbiológico de difusão em ágar (cilindros em placas) é valido e constitui-se, assim, em uma metodologia alternativa, econômica e de fácil execução para a determinação da potência de antimicrobianos. Demonstrando linearidade e precisão adequada o método mostrou-se ser útil no doseamento desses fármacos em preparações farmacêuticas.

\section{REFERÊNCIAS}

BREIER, A. R.; GARCIA, C. V.; OPPE, T. P.; STEPP, M.; SCHAPOVAL, E. E. S. Microbiological assay for azithromycin in pharmaceutical formulations. Journal of Pharmaceutical and Biomedical Analysis. v.29, n.5, p.957-
61, 2002.

FARMACOPÉIA Brasileira. 4. ed. São Paulo: Atheneu, 1988.

FRÖEHLICH, P. E.; SCHAPOVAL, E. E. S. Doseamento microbiológico do norfloxacino, método da difusão em ágar (cilindro em placas). Rev. Ciênc. farm. São Paulo. v.12, p.161-65, 1990.

FUCHS, F.D.; WANNMACHER, L. Farmacologia clínica: fundamentos da terapêutica racional. 2 ed. Rio de Janeiro: Guanabara Koogan, 1998. 678 p.

GOODMAN, L. S.; GILMAN, A. Godman \& Gilman's the pharmacological basis of therapeutics. 9 ed. New York: MacGraw-Hill, 1996.

LUIZA, V. L.; CASTRO, C. G. S. O.; NUNES, J. M. Aquisição de medicamentos no setor público: o binômio qualidade - custo. Cad. Saúde Pública. Rio de Janeiro. v.15, n.4, p. 769-76, 1999.

KONEMAN, E. W.; ALLEN, S. D.; JANDA, W. A.; SCHRECKNBERGER, P. C.; WIM, W. C. Jr. Diagnóstico Microbiológico: texto e atlas colorido. 5 ed. Rio de Janeiro: Medsi, 2001. 1465 p.

MARTINDAILE: the extra phamacopeia. 29. ed. London: The Pharmaceutical, 1989. 1896 p.

NCCLS (NATIONAL COMMTTEE FOR CLINICAL LABORATORY STANDARDS). Performance Standards for Antimicrobial Susceptibility Testting. Wayne: NCCLS, 2002. $133 \mathrm{p}$

RANG, H. P.; DALE, M. M.; RITTER, J.M. Farmacologia. 4.ed. Rio de Janeiro: Guanabara-Koogan, 2001. 703 p.

TURCINOV, T.; PEPELJNJAK, S. Azithromycin potency determination: optimal conditions for microbiological diffusion method assay. Journal of Pharmaceutical and Biomedical Analysis. v. 17, p.903-910, 1998.

UNITED STATES PHARMACOPEIA CONVENTION. The united states pharmacopeia: the national formulary. 22. ed. Easton: USP, 1990. 2067 p. 